\title{
Can heat-pressed feldspathic ceramic be submitted to multiple heat-pressing?
}

\begin{abstract}
Amanda Maria de Oliveira DAL PIVA ${ }^{(a)}$ Aline Serrado de Pinho BARCELLOS(a)

Marco Antonio BOTTINO(a) Rodrigo Othávio de Assunção e SOUZA ${ }^{(b)}$ Renata Marques de MELO(a)
\end{abstract}

(a) Universidade Estadual Paulista - Unesp, Institute of Science and Technology, Department of Dental Materials and Prosthodontics, São José dos Campos, SP, Brazil.

(b) Universidade Federal do Rio Grande do Norte - UFRN, Department of Dentistry, Division of Prosthodontics, Natal, RN, Brazil.

Declaration of Interest: The authors certify that they have no commercial or associative interest that represents a conflict of interest in connection with the manuscript.

\section{Corresponding Author:}

Renata Marques de Melo

E-mail: marquesdemelo@gmail.com

Submitted: February 18, 2018

Accepted for publication: August 01, 2018

Last revision: August 29, 2018
Abstract: The aim of this study was to determine if multiple processing (heat-pressing) of a dental ceramic influences flexural strength, hardness, and microstructure. Ninety bar-shaped specimens $(15 \mathrm{~mm} \times 4 \mathrm{~mm} \times 2 \mathrm{~mm})$ of a pressed ceramic (Vita PM9) were fabricated and randomly divided into 6 groups $(\mathrm{n}=15)$ according to the factors "number of pressings" ( $\mathrm{C} 1, \mathrm{C} 2$, and $\mathrm{C} 3$, fired 1,2 , and 3 times, respectively) and "mechanical cycling" (M). Half of the specimens were mechanically cycled $\left(10^{6}\right.$ cycles, $45 \mathrm{~N}, 3.4 \mathrm{~Hz}$, in water $)$ and all specimens were tested for 3-point bending $(0.5 \mathrm{~mm} / \mathrm{min}$, load $1000 \mathrm{kgf}$ ) and Vickers hardness (19.6 N for $20 \mathrm{~s}$ ). X-ray diffraction was used to characterize the phases and scanning electron microscopy to characterize the microstructure. The flexural strength data was statistically analyzed with Weibull analysis, ANOVA, and Tukey test. Hardness data was evaluated by 2-way ANOVA and Fisher test. All tests were performed with a significance level of 0.05 . Two-way ANOVA revealed that neither "number of pressings" $(p=0.085)$ or "mechanical cycling" (0.055) significantly affected flexural strength. But Weibull analysis showed significant difference for Weibull moduli and characteristic strength between groups. For hardness, a statistical difference was seen for the interaction "Number of pressings * Mechanical cycling", $(p=0.016)$. Hardness decreased in the following order: C1 (775 \pm 17.2$),$ CM3 (751 \pm 101$), C M 2$ (735 \pm 45$), C 3$ (701 \pm 82$), C M 1(671 \pm 82)$, and C2 (663 \pm 92$)$. Fewer defects were observed with an increased number of firings. Therefore, the possibility of recycling PM9 ceramic does not interfere in the evaluated mechanical properties and improves microstructure.

Keywords: Recycling; Ceramics; Stress, Mechanical; Hardness.

\section{Introduction}

The development of dental materials has been important to meet aesthetic issues in oral rehabilitation, ${ }^{1}$ promoting increased use of aesthetic restorative materials and the development of dental ceramics. ${ }^{2}$ Important properties of ceramic materials are chemical stability, biocompatibility, and the thermal expansion coefficient, ${ }^{3}$ as well as high resistance to compression and wear. ${ }^{4,5,6,7}$ Glass ceramics have the disadvantage of having low fracture toughness, which facilitates crack propagation, causing restoration failure. ${ }^{8}$ 
Feldspathic ceramic is one type of glass-matrix ceramic compound of hydrated aluminosilicate, silica, and feldspat. ${ }^{9}$ Various systems for making ceramic inlays have been marketed since the early 1980's: heat-press, stratification, and CAD/ CAM technology (Computer Aided Design/ Computer Aided Manufacturing). ${ }^{10}$ The heatpress technique minimizes internal porosity ${ }^{11,12}$ improving the clinical performance; it has become very popular in dental laboratories because it is easy to use. Monochrome porcelain is pressed to reproduce the optical characteristics of the tooth, and depending on the extrinsic painting techniques, it is possible to improve the aesthetics of the prosthetic restoration. VITA PM9 (Vita Zahnfabrik) is a heat-pressed feldspathic ceramic, composed of fine feldspathic structures developed from the VITA VM9 veneering ceramic; both are leucite-based materials. According to the manufacturer, it can be used for inlay and onlay restorations, and for over-injecting infrastructures.

Heat-pressable ceramics are available in ingots of predefined sizes that are usually not completely used, resulting in leftovers. It has been questioned if pressed ceramics that were used to fill the sprue and feed ring can be recycled without influencing their quality. ${ }^{13}$ Recent studies found a positive influence of multiple firing on roughness, flexural strength, and hardness of several ceramics, although most were lithium disilicate-based materials. ${ }^{14,15}$ The possibility of re-using the leftover ceramics can be seen as a financial advantage for some laboratories and clinicians. Moreover, it is an environmentally friendly solution for materials that would just be discarded.

Due to the lack of studies assessing the influence of re-pressing leucite ceramic on its properties, this study aimed to assess the influence of re-pressing on strength, hardness, and on the microstructure of a leucite-based pressable ceramic after multiple pressings. The null hypothesis was that repeated pressing does not influence flexural strength, microhardness, and microstructure neither prior nor after mechanical cycling.

\section{Methodology}

\section{Preparation of ceramic bars}

Wax blocks (Bego) were cut into standardized bars of $18 \times 4.5 \times 2.5 \mathrm{~mm}$. Next, the bars were fixed in a wax feed channel (sprue) with a length of $3 \mathrm{~mm}$ and a minimum diameter of $4 \mathrm{~mm}$ with rounded connection points. In one development, the base is connected to wax sprues and four sets of blocks at an angle of $45^{\circ}$, with a minimum distance of $10 \mathrm{~mm}$ from the ring wall. The investments (Bellavest $\mathrm{SH}$, Bego, Bremen, Germany) were handled according to manufacturer's instructions and transferred to the ring. After solidification, the investments were inserted in a preheated oven at $850^{\circ} \mathrm{C}$ (EDG3P-S 1800) for at least 75 minutes for complete wax and polymer evaporation. The investments were quickly transferred to another oven (Vita Vacumat MP 6000, Vita Zahnfabrik, Bad Säckingen, Germany) and Vita PM9 ingots (Vita Zahnfabrik, Bad Säckingen, Germany) were inserted and injected with a pressure of 3 bars according to the manufacturer's recommendations. After cooling, the bars were removed from the investment and cleaned with $50 \mu \mathrm{m}$ aluminum oxide particles (Asfer Indústria Química Ltda, São Caetano do Sul, Brazil) (Professional Jet, EDG, PRO-ANALYSIS Chemical and Diagnostics Ltd, Cotia, Brazil) with a pressure of 2 bars (to remove investment remains) and then washed with isopropyl alcohol in an ultrasonic bath for $5 \mathrm{~min}$.

The bars were standardized with $\mathrm{SiC}$ sandpaper \# 320,400 , and $600 \mu \mathrm{m}$ until reaching final dimensions of $15 \times 4 \times 2 \mathrm{~mm}$ in an automatic polisher (EcoMet/ AutoMet250, Buehler, USA) using a metal device that holds the surface straight. Then, the samples were polished with decreasing grit sandpaper until $1200 \mu \mathrm{m}$ following ISO 6872. The samples $(\mathrm{n}=90)$ were divided into six groups $(n=15)$ according to the factors: "number of pressings" and "mechanical cycling - M": C1 (control group - 1 pressing), C2 (2 pressings), C3 (3 pressings), CM1 (C1 + mechanical cycling), CM2 (C2 + mechanical cycling), and CM3 (C3 + mechanical cycling). Thirty bars were initially made with a single pressing. For groups with two pressings, ingots were pressed twice $(n=30)$. For the groups with three pressings, the ingots were pressed 3 times until the ceramic bars were obtained. 


\section{Mechanical cycling}

Mechanical cycling (ER- 11000, Technical and Scientific Erios Equipment Ltda, São Paulo, Brazil) was performed with a three-point bending device with a distance of $16 \mathrm{~mm}$ between the supports. Only the sample's extremities were supported, therefore the central region received the load from a device attached to the machine $\left(45 \mathrm{~N}, 10^{6}\right.$ cycles, $3.4 \mathrm{~Hz}$, water, $\left.37^{\circ} \mathrm{C}\right)$. The load was applied by a piston with $1 \mathrm{~mm}$ diameter.

\section{Flexural strength}

Flexural strength was measured using the three-point bending test that consists of a bar supported by two cylinders ( $2 \mathrm{~mm}$ of diameter) with $15 \mathrm{~mm}$ distance between the centers. Compression $\left(0.5 \mathrm{~mm} / \mathrm{min}, 1000 \mathrm{Kgf}, 20 \pm 1^{\circ} \mathrm{C}\right)$ until catastrophic failure ${ }^{16}$ was applied with relative humidity of $70 \pm 5 \%$, following ISO 6872 guidelines. The flexural strength was calculated using the formula: $F S=\frac{3}{2} \times \frac{F l}{C h 2}$. Where, $F$ is the failure load in Newtons, $l, h$, and $c$ are respectively the bar's length, height, and width.

\section{Hardness}

After the three-point bending test, six fragments of bending specimens from each group were randomly chosen for the Vickers microhardness test using a Vickers tester (VMT-7, Buehler, City, Country) with a load of $19.6 \mathrm{~N}$ for $20 \mathrm{~s}$. All samples were embedded in acrylic resin for stability and regularity during the analysis. The samples were then polished using SiC sandpaper \#1200 and cleaned in an ultrasonic bath with isopropyl alcohol (5 min). The hardness data $(\mathrm{VH})$ was calculated by the value of the applied load, the diagonal length, and the angle between the opposite faces of the indentator ${ }^{17,18}$ in six indentations per sample.

\section{X-ray diffraction (XRD)}

X-ray diffraction analysis was performed in two samples of each group to determine the possible changes in the crystalline phase and microstructure induced by processing protocols. The analysis was performed using an X-ray diffractometer (PHILIPS, PW, 1830, Georgia, USA). The crystalline phases present in two samples of each group were identified using $\mathrm{Cu}-\mathrm{K \alpha}$ $\mathrm{x}$-rays between 20 and 60 degrees, 0.020 step and a speed of 1s/point counting. The data were analyzed by graphs using a computer program (Oring 8.0).

\section{Scanning Electron Microscopy (SEM)}

SEM was performed to analyze the microstructure of the material $(\mathrm{n}=2)$ after slightly etching the surface with $10 \%$ hydrofluoric acid during $60 \mathrm{~s}$, following manufacturer recommendation for surface treatment. Fractured surfaces were also evaluated for differences inside the material. The samples were included in a sample holder with carbon double-sided adhesive tape (SPI) to visualize surface topography. The samples were sputtered with gold-palladium alloy (Polaron SC 7620 Sputter Coater, Technologies Quorum, Newhaven, United Kingdom) for $130 \mathrm{~s}$, with a current of 10-15 mA, $130 \mathrm{mTorr}$ vacuum, plate rate: $3.5 \mathrm{~nm} / \mathrm{min}$, and $\mathrm{Pd}-\mathrm{Au}$ layer of about $80 \AA$ A. SEM (Inspect S50, FEI Company, Brno, Czech Republic) was operated on $15 \mathrm{kV}$.

\section{Statistical analysis}

After evaluating data homogeneity and normality (Kolmogorov-Smirnoff), flexural strength data was subjected to Weibull, two-way ANOVA and Tukey test $(\alpha=0.05)$. Hardness results were submitted to two-way ANOVA and Fisher's tests $(\alpha=0.05)$. The data were statistically analyzed with Statistix 9 software (Statistix 9.0) and Minitab software (Minitab 17 for Windows, 2004). XRD and SEM data were analyzed qualitatively.

\section{Results}

\section{Flexural strength}

Two-way ANOVA (Table 1) showed that neither "number of pressings" $(\mathrm{p}=0.085)$ nor "mechanical cycling" (0.055) significantly affected flexural strength. The reliability of the groups was evaluated through Weibull analysis. According to chi-square and Bonferroni 95\% tests, the Weibull moduli (m) and characteristic strength $\left(\sigma_{0}\right)$ of the groups were statistically different (Table). This data indicated that CM2 specimens presented improved structural homogeneity, and thus a more predictable performance until failure, but were statistically similar to C2, C3, and CM1. The worst reliability data occurred for $\mathrm{CM} 3$ and for the control group. 


\section{Hardness}

Two-way ANOVA showed significant difference for the interaction "Number of pressings * Mechanical Cycling", with $\mathrm{p}=0.016$ (Table 1). According to Fisher's test (Table), the control group (C1) presented the highest mean value (775.8), statistically similar to C3, CM2 and CM3.

\section{XRD}

According to $\mathrm{XRD}$, the major peaks observed for all groups were from potassium aluminum silicate (Leucite) (Figure 1) at 28 degrees. The graphs show that the crystalline phase did not change after multiple firings.

\section{SEM}

According to surface micrographs od specimens without acid etching (230x), the group with one heatpress was visually more porous (Figure 2). SurfaceSEM images showed that all groups presented porosities after conditioning with $10 \%$ hydrofluoridric gel $(7000 \mathrm{x})$. However, qualitative analysis of the group submitted to three heat-pressings seemed to have a higher number of pores. The presence of more leucite crystals was also observable after two and three pressings (Figure 3).

\section{Discussion}

The results demonstrated that repeatedly pressing PM9 created a microstructure with fewer defects, without influence on flexural strength. In the shortterm, one heat-press resulted in the highest mean value for hardness. However, in the long-term, there was no influence from the number of pressings. Therefore, the hypothesis that repeated pressing does not influence the mechanical properties or the microstructure was not accepted given that although a decreased number of pores and an increased number of leucite crystals maintained the flexural strength and the hardness, hardness decreased after mechanical aging with only one pressing.

Increasing the number of pressings seemed to have better condensed the material decreasing the number of pores (Figure 2), but this change did not result in flexural strength differences. It is known that ceramics have residual stress from manufacturing and that reprocessing may relieve this stress. ${ }^{14}$ Studies have shown that flexural strength also depends on the ceramic surface finishing and the correct beveling of the edges, such as done in this study. ${ }^{14,16,19}$ No change in flexural strength was observed in previous studies

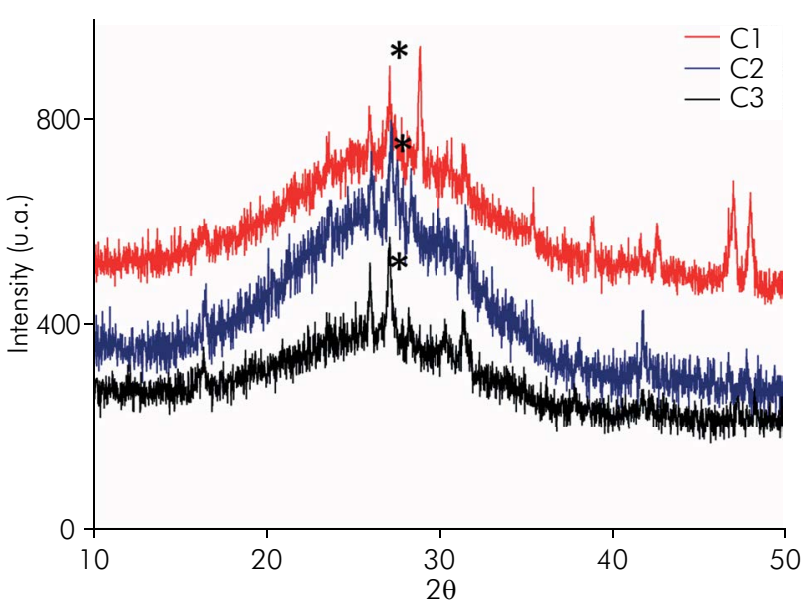

Figure 1. XRD graphs of C1, C2, and C3 groups. Asterisks represent the predominant peak of leucite.

Table. Means and standard deviation (SD) of mechanical properties of the groups. Characteristic strength $(\sigma 0)$, Weibull modulus $(\mathrm{m})$ and respective coefficient intervals $(\mathrm{Cl})$, and correlation for flexural strength.

\begin{tabular}{lccccccc}
\hline \multirow{2}{*}{ Group } & \multicolumn{3}{c}{ Flexural strength } & \multicolumn{3}{c}{ Weibull } & \multicolumn{2}{c}{ Hardness } \\
\cline { 2 - 7 } & Mean $(\mathrm{SD})$ & $\mathrm{m}(\mathrm{p}<0.001)$ & $\mathrm{Cl}$ & $\sigma_{0} p<0.000$ & $\mathrm{Cl}$ & Corr & Mean $(\mathrm{SD})$ \\
\hline $\mathrm{C} 1$ & $130.5(38.9)$ & $4.45^{\mathrm{B}}$ & $3.51-5.65$ & $142^{\mathrm{B}}$ & $125-160$ & 0.94 & $775.83(17.2)^{\mathrm{A}}$ \\
$\mathrm{C} 2$ & $147.7(31.7)$ & $6.12^{\mathrm{AB}}$ & $4.61-8.11$ & $158^{\mathrm{A}}$ & $144-173$ & 0.91 & $663(92.6)^{\mathrm{B}}$ \\
$\mathrm{C} 3$ & $121.3(18.6)$ & $7.82^{\mathrm{AB}}$ & $5.73-10.69$ & $128^{\mathrm{B}}$ & $120-138$ & 0.96 & $701.2(82.2)^{\mathrm{AB}}$ \\
$\mathrm{CM} 1$ & $142.1(28.5)$ & $6.14^{\mathrm{AB}}$ & $4.42-8.53$ & $152^{\mathrm{A}}$ & $139-166$ & 0.95 & $671.7(82.3)^{\mathrm{B}}$ \\
$\mathrm{CM} 2$ & $151.0(19.2)$ & $9.58^{\mathrm{A}}$ & $7.00-13.0$ & $158^{\mathrm{A}}$ & $150-168$ & 0.96 & $735(45.5)^{\mathrm{AB}}$ \\
$\mathrm{CM} 3$ & $143.8(38.3)$ & $4.21^{\mathrm{B}}$ & $2.77-6.40$ & $158^{\mathrm{A}}$ & $139-179$ & 0.97 & $751.7(101.7)^{\mathrm{AB}}$ \\
\hline
\end{tabular}



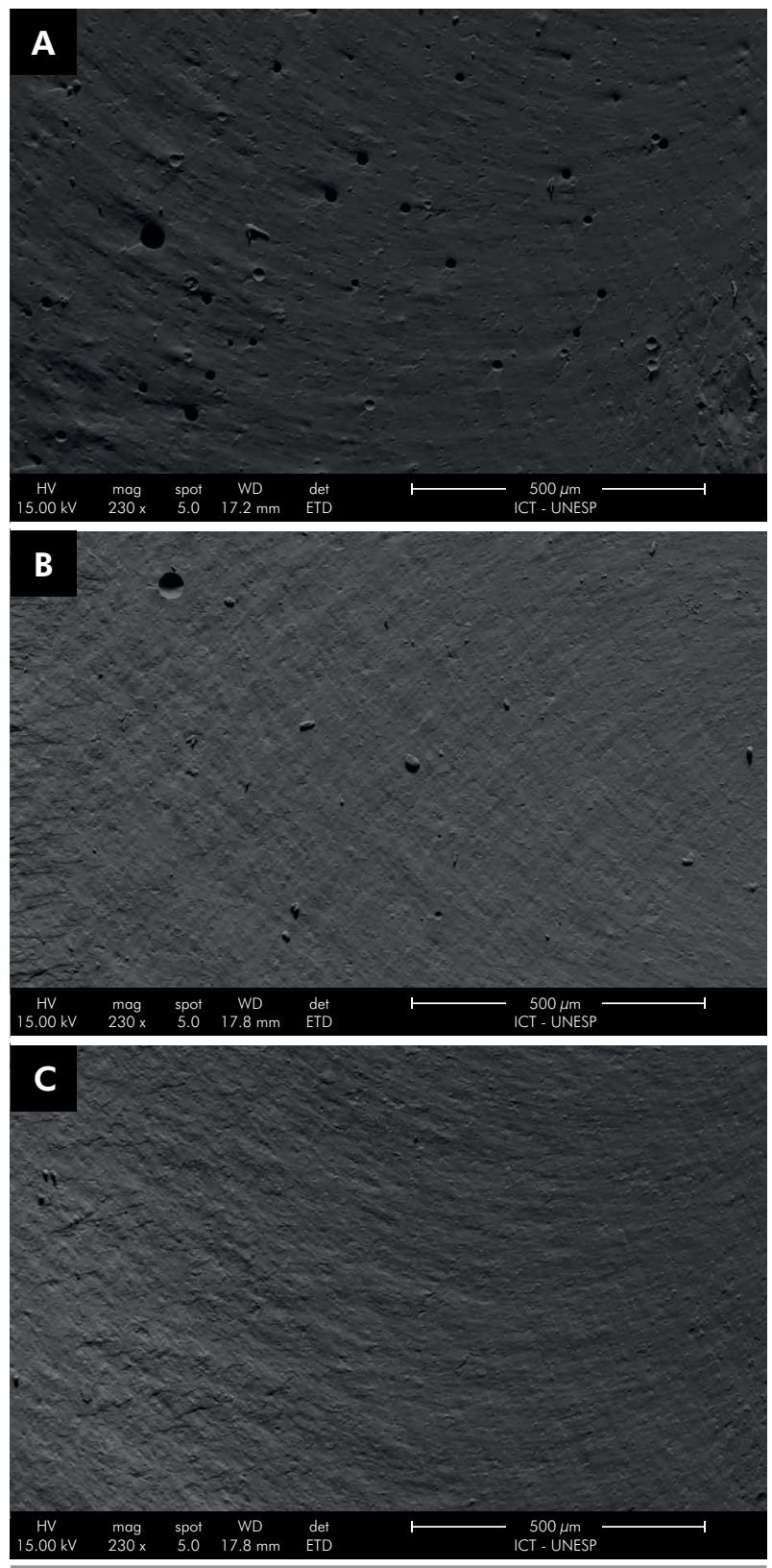

Figure 2. Representative SEM images of fracture surfaces from A) $\mathrm{C} 1$; B) C2, and C) C3 groups. Several pores are seen in C1.

for other leucite-reinforced and lithium disilicate glass ceramic (Ivoclar-Vivadent, Schaan, Liechtenstein). ${ }^{13,14}$ However, the mean biaxial flexural strength of feldspathic or lithium disilicate ceramics were not significantly decreased with multiple pressings. In this study, when the samples were reprocessed and submitted to mechanical cycling, the performance was similar to those that were only reprocessed, endorsing the possibility of recycling this material. No data is available for direct comparison to the mechanically cycled groups. A previous study evaluated the effect of number of firings on flexural strength and hardness of different veneer ceramics, suggesting that higher mean values of flexural strength and hardness could be related to lower porosity and higher density after several firings. ${ }^{15}$ However, the procedure of re-injection or pressing was not studied in that paper.

Weibull analysis was used for assessing the structural reliability according to the number of pressings and aging. The present results disagree with a recent study ${ }^{13}$ that affirmed that a second firing may promote a less homogeneous structure. On the contrary, two and three pressings before mechanical cycling seemed to improve the homogeneity as a higher Weibull modulus indicates less variation in the size, amount, and distribution of defects in the material..$^{20}$ Thus, it is also important to perform the moduli comparison to detect differences in reliability, ${ }^{21,22,23,24}$ although a sample size higher than 15 (preferably 30) is recommended to decrease the uncertainties. ${ }^{25}$ Also, Weibull analysis showed statistically lower mean values in strength for $\mathrm{C} 1$ and $\mathrm{C} 3$, which was the stress at which $63 \%$ of the specimens failed.

The hardness test showed that the control group (without repeated pressing) presented the highest mean values, but values were statistically similar to C3, CM2, and CM3. The literature is not clear about the effects of repeated pressing on the hardness of other ceramics. For a heat-pressed lithium disilicate, the Vickers hardness decreased with the increased number of pressings, but without statistical significance. ${ }^{14}$ Herein, two pressings decreased material hardness, but three pressings provided hardness similar to the control group. For aged samples, there was no difference between the groups. Another study evaluated the number of firings in veneer ceramics and showed that Vickers hardness was significantly higher for VM9 fired up to 10 times. ${ }^{15}$ However, the reason for this remains unclear. It is important to notice that repeated processing promoted durable hardness values.

XRD demonstrated that leucite was present in all groups with no difference among them, although the peak intensities were not quantified in our study. Also, the glass matrix phase was detected 

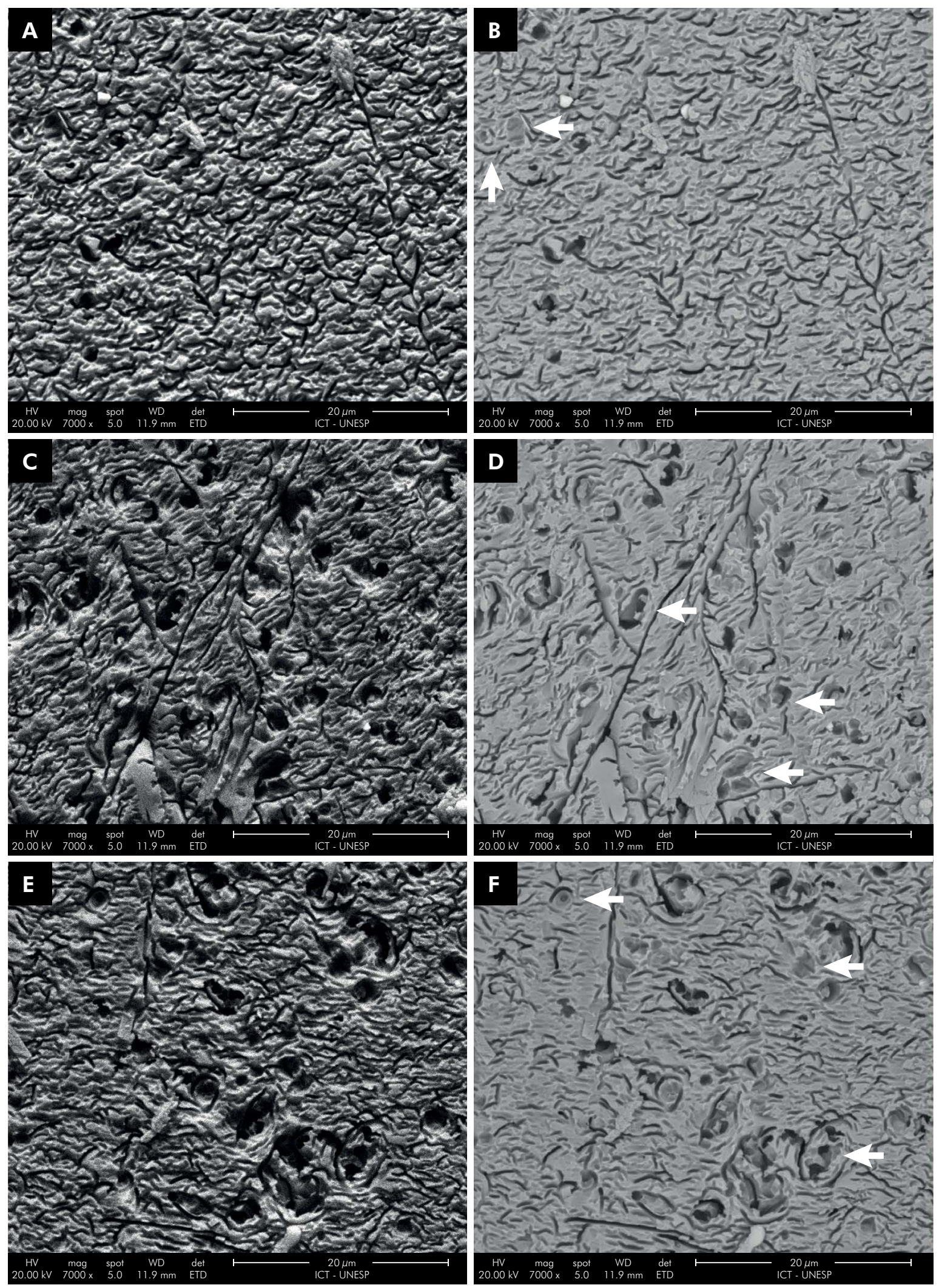

Figure 3. Micrographs (7000x) with secondary electron detectors (ETD - Everhart Thornley Detector) and back-scattered electron detector (BSED) of a representative sample from ( $A$ and $D) C 1,(B$ and $E) C 2$ and $(C$ and $F) ~ C 3$ groups. White arrows indicate leucite grains. 
as an amorphous phase. No additional phase was observed and peaks remained unchanged with repeated processing, as observed in a previous study. ${ }^{14}$ According to SEM images (Figure 3), microcracks were present in the glass matrix in the beginning for all groups. A quantitative analysis is necessary to determine the number and size of leucite grains and the size of microcracks after two and three processing cycles. The increased defects can be justified by the thermal expansion mismatch of leucite grains and glass matrix during cooling. ${ }^{13}$ On the other hand, increase in grain size and in secondary crystals due to recrystallization of the crystals at specific temperatures during repeated pressing may have occurred. ${ }^{14}$ This can justify the increase in the number of leucite crystals according to the number of injections observed on the qualitative SEM (Figure 3). In the present study, the free spaces were possibly decreased due to crystal growth or because residual glass phase occupied the pores left by the previous injection. A more uniform microstructure and leucite crystal size can thus be related to the increase in biaxial flexural strength. ${ }^{26}$

In this study, all samples were submitted to aging by mechanical fatigue to investigate the influence of the number of pressings on the long-term mechanical properties. The aging protocol followed a recently published paper that studied the effects of simulated mechanical cycling on a glass ceramic. ${ }^{27}$ The authors

\section{References}

1. Ozturk N, Aykent F. Dentin bond strengths of two ceramic inlay systems after cementation with three different techniques and one bonding system. J Prosthet Dent. 2003 Mar;89(3):275-81. https://doi.org/10.1067/mpr.2003.37

2. Oztürk AN, Inan O, Inan E, Oztürk B. Microtensile bond strength of cad-cam and pressed-ceramic inlays to dentin. Eur J Dent. 2007 Apr;1(2):91-6.

3. Soares CJ, Soares PV, Pereira JC, Fonseca RB. Surface treatment protocols in the cementation process of ceramic and laboratory-processed composite restorations: a literature review. J Esthet Restor Dent. 2005;17(4):224-35. https://doi.org/10.1111/j.1708-8240.2005.tb00119.x

4. Abel MG. In-office inlays with today's new materials. Dent Clin North Am. 1998 Oct;42(4):657-64. applied a load bellow critical level, but capable of promoting crack nucleation and slow crack growth in brittle materials. Regarding the number of cycles, 500,000 cycles is considered the functioning of a restored tooth in a year. Thus, $10^{6}$ mechanical cycles were performed to represent 2 years of service. ${ }^{27,28,29}$

The release of residual stress may have been responsible for the increase in flexural strength for $\mathrm{C} 1$ and $\mathrm{C} 2$ aged-groups. ${ }^{30,31}$ Future studies should address the quantification of leucite crystals through XRD or similar techniques, and the effects of such crystals on the residual stress after repeated pressings.

\section{Conclusion}

Within this study's limitations, it may be concluded that multiple pressings did not affect the evaluated mechanical properties in the long-term or changed the microstructure. Therefore, the possibility of submitting PM9 ceramic to repeated pressing was demonstrated within certain limitations, as the material was not evaluated over an infrastructure.

\section{Acknowledgments}

The authors are very grateful to Professor Fernanda Campos collaboration in specimen preparation and to Professor Thaís Cachuté Paradella for providing the scanning electron microscopy images.

5. Fradeani M, Aquilano A, Bassein L. Longitudinal study of pressed glass-ceramic inlays for four and a half years. J Prosthet Dent. 1997 Oct;78(4):346-53. https://doi.org/10.1016/S0022-3913(97)70041-6

6. Van Meerbeek B, Perdigão J, Lambrechts P, Vanherle G. The clinical performance of adhesives. J Dent. 1998 Jan;26(1):1-20. https://doi.org/10.1016/S0300-5712(96)00070-X

7. Almeida AA Jr, Longhini D, Domingues NB, Santos C, Adabo GL. Effects of extreme cooling methods on mechanical properties and shear bond strength of bilayered porcelain/3Y-TZP specimens. J Dent. 2013 Apr;41(4):356-62. https://doi.org/10.1016/i.jdent.2013.01.005

8. Correr Sobrinho L, Cattell MJ, Glover RH, Knowles JC. Investigation of the dry and wet fatigue properties of three all-ceramic crown systems. Int J Prosthodont. 1998 May-Jun;11(3):255-62. 
9. Gracis S, Thompson VP, Ferencz JL, Silva NR, Bonfante EA. A new classification system for all-ceramic and ceramiclike restorative materials. Int J Prosthodont. 2015 MayJun;28(3):227-35. https://doi.org/10.11607/iip.4244

10. Valandro L, Bottino MA. Cimentação adesiva de restaurações cerâmicas. In: Bottino MA, editor. Percepção: estética em próteses livres de metal em dentes naturais e implantes. São Paulo: Artes Médicas; 2009. p. 469-542.

11. Ansong R, Flinn B, Chung KH, Mancl L, Ishibe M, Raigrodski AJ. Fracture toughness of heat-pressed and layered ceramics. J Prosthet Dent. 2013 Apr;109(4):234-40. https://doi.org/10.1016/S0022-3913(13)60051-7

12. Isgrò $G$, Pallav P, Zel JM, Feilzer AJ. The influence of the veneering porcelain and different surface treatments on the biaxial flexural strength of a heat-pressed ceramic. J Prosthet Dent. 2003 Nov;90(5):465-73. https://doi.org/10.1016/i.prosdent.2003.08.003

13. Albakry M, Guazzato M, Swain MV. Biaxial flexural strength and microstructure changes of two recycled pressable glass ceramics. J Prosthodont. 2004 Sep;13(3):141-9. https://doi.org/10.1111/j.1532-849X.2004.04025.x

14. Gorman CM, Horgan K, Dollard RP, Stanton KT. Effects of repeated processing on the strength and microstructure of a heat-pressed dental ceramic. J Prosthet Dent. 2014 Dec;112(6):1370-6. https://doi.org/10.1016/i.prosdent.2014.06.015

15. Tang $X$, Luo $H$, Bai $Y$, Tang H, Nakamura T, Yatani $\mathrm{H}$. Influences of multiple firings and aging on surface roughness, strength and hardness of veneering ceramics for zirconia frameworks. J Dent. 2015 Sep;43(9):1148-53. https://doi.org/10.1016/j.jdent.2015.06.006

16. Della Bona A, Anusavice KJ, Hood JA. Effect of ceramic surface treatment on tensile bond strength to a resin cement. Int J Prosthodont. 2002 May-Jun;15(3):248-53.

17. Lazar DR, Bottino MC, Ozcan M, Valandro LF, Amaral R, Ussui $V$ et al. Y-TZP ceramic processing from coprecipitated powders: a comparative study with three commercial dental ceramics. Dent Mater. 2008 Dec;24(12):1676-85. https://doi.org/10.1016/i.dental.2008.04.002

18. lost A, Bigot R. Hardness of coatings. J Mater Sci. 1996 Jan;31(13):3573-7. https://doi.org/10.1007/BF00360764

19. Bona AD, Anusavice KJ, DeHoff PH. Weibull analysis and flexural strength of hot-pressed core and veneered ceramic structures. Dent Mater. 2003 Nov;19(7):662-9. https://doi.org/10.1016/S0109-5641(03)00010-1

20. Elsaka SE, Elnaghy AM. Mechanical properties of zirconia reinforced lithium silicate glass-ceramic. Dent Mater. 2016 Jul;32(7):908-14. https://doi.org/10.1016/i.dental.2016.03.013
21. Missau T, Bello MC, Michelon C, Mastella Lang P, Pereira GK, Baldissara $\mathrm{P}$ et al. Influence of Endodontic Treatment and Retreatment on the Fatigue Failure Load, Numbers of Cycles for Failure, and Survival Rates of Human Canine Teeth. J Endod. 2017 Dec;43(12):2081-7. https://doi.org/10.1016/i.joen.2017.07.013

22. Pereira GK, Amaral M, Simoneti R, Rocha GC, Cesar PF, Valandro LF. Effect of grinding with diamond-disc and -bur on the mechanical behavior of a Y-TZP ceramic. J Mech Behav Biomed Mater. 2014 Sep;37:133-40. https://doi.org/10.1016/i.jmbbm.2014.05.010

23. Pereira G, Amaral M, Cesar PF, Bottino MC, Kleverlaan $C J$, Valandro LF. Effect of low-temperature aging on the mechanical behavior of ground Y-TZP. J Mech Behav Biomed Mater. 2015 May;45:183-92. https://doi.org/10.1016/i.jmbbm.2014.12.009

24. Pozzobon JL, Pereira GK, Wandscher VF, Dorneles LS, Valandro LF. Mechanical behavior of yttria-stabilized tetragonal zirconia polycrystalline ceramic after different zirconia surface treatments. Mater Sci Eng C. 2017 Aug;77:828-35. https://doi.org/10.1016/i.msec.2017.03.299

25. Quinn JB, Quinn GD. A practical and systematic review of Weibull statistics for reporting strengths of dental materials. Dent Mater. 2010 Feb;26(2):135-47. https://doi.org/10.1016/j. dental.2009.09.006 PMID:19945745 V. The effect of microstructural features on the biaxial flexural strength of leucite reinforced glass-ceramics. J Mater Sci. 1994;5(2):113-8.

26. Barcellos ASP, Marinho CC, Miranda JS, Amaral M, Shiino MY, Kimpara ET. Effect of fatigue protocols on flexural strength of lithium disilicate bars with clampedends. J Mech Behav Biomed Mater. 2018 May;81:173-7. https://doi.org/10.1016/i.jmbbm.2018.02.007

27. Kelly JR. Ceramics in restorative and prosthetic dentistry. Annu Rev Mater Sci. 1997;27(1):443-68 https://doi.org/10.1146/annurev.matsci.27.1.443

28. Wang RR, Lu CL, Wang G, Zhang DS. Influence of cyclic loading on the fracture toughness and load bearing capacities of all-ceramic crowns. Int J Oral Sci. 2014 Jun;6(2):99-104. https://doi.org/10.1038/ijos.2013.94

29. Rodriguez O, Matinmanesh A, Phull S, Schemitsch EH, Zalzal $\mathrm{P}$, Clarkin $\mathrm{OM}$ et al. Silica-Based and Borate-Based, TitaniaContaining Bioactive Coatings Characterization: Critical Strain Energy Release Rate, Residual Stresses, Hardness, and Thermal Expansion. J Funct Biomater. 2016 Dec;7(4):E32. https://doi.org/10.3390/ifb7040032

30. Von Maltzahn NF, Kleibe M, Stiesch M, Hübsch C, Kohorst P. Interfacial adhesion of zirconia/veneer bilayers with different thermal characteristics. Dent Mater J. 2014;33(5):583-90. https://doi.org/10.4012/dmi.2013-181 